\title{
The impact of fisheries management practices on the survival of the Yangtze finless porpoise in China
}

Zhigang Mei ${ }^{1}$, Yi Han ${ }^{1}$, Lijun Dong ${ }^{1}$, Samuel T Turvey ${ }^{2}$, Yujiang Hao ${ }^{1}$, Kexiong

Wang ${ }^{1,}$, Ding Wang, ${ }^{1, *}$

${ }^{1}$ Key Laboratory of Aquatic Biodiversity and Conservation, Institute of Hydrobiology, Chinese Academy of Sciences, Wuhan 430072, China

${ }^{2}$ Institute of Zoology, Zoological Society of London, Regent's Park, London NW1 4RY, UK

Email addresses: meizhigang@ihb.ac.cn (Z. Mei), hanyi@ihb.ac.cn (Y. Han),

Donglj@sidsse.ac.cn (L. Dong), samuel.turvey@ioz.ac.uk (S. T. Turvey), hao.yj@ihb.ac.cn (Y.

Hao), wangk@ihb.ac.cn (K. Wang), wangd@ihb.ac.cn (D Wang).

Running title: Unintended outcomes of porpoise conservation

Keywords: behavioural change; community interviews; freshwater cetacean; fisheries compensation; insufficient conservation management; perverse effect

\footnotetext{
*Author for correspondence; current address: Key Laboratory of Aquatic Biodiversity and Conservation, Institute of Hydrobiology, Chinese Academy of Sciences, Wuhan 430072, China, email: wangk@ihb.ac.cn, wangd@ihb.ac.cn
} 


\section{Abstract}

1. The Critically Endangered Yangtze finless porpoise (Neophocaena asiaeorientalis asiaeorientalis) is facing a significant threat from illegal fishing in Poyang Lake and Dongting Lake, and current fisheries management has proved insufficient to eliminate illegal fishing.

2. We conducted a survey of local communities around the two lakes to investigate fishing activities and their potential impacts. Using a series of six scenarios derived from our data, we suggest that enhanced daytime patrols may have driven fishers to conduct compensatory nighttime fishing when patrols are absent. Nighttime fishing activities overlap temporally with the main period of Yangtze finless porpoise foraging, so that potential intensification of nighttime fishing with use of illegal gears could pose an increased threat to porpoises.

3. In addition to increasing law enforcement management efforts, helping fishers to pursue secure alternative livelihoods may provide a more practical and sustainable long-term method for reducing illegal fishing and its impacts on porpoises. This study can provide important lessons for conservation policy-making and implementation for other cetacean species threatened by illegal fishing.

Keywords: freshwater cetacean; community interviews; insufficient conservation management; fisheries compensation; behavioural change; perverse effect 


\section{Introduction}

The Critically Endangered Yangtze finless porpoise (Neophocaena asiaeorientalis asiaeorientalis) is the only freshwater porpoise in the world, and is endemic to the middle and lower reaches of the Yangtze River and its two adjoining lakes, Poyang Lake and Dongting Lake (Gao \& Zhou, 1995; Jefferson \& Wang, 2011; Turvey et al., 2007). Intensive anthropogenic disturbances in the Yangtze ecosystem, including construction, sand dredging, overfishing, by-catch in both legal and illegal fishing gear, busy water traffic and pollution, have had a severe impact on the wild Yangtze finless porpoise population (Wang et al., 2000; Zhao et al., 2008). Its total population has fallen to about 1,000 individuals (Mei et al., 2014), and it has been estimated that the population in the mainstem of the Yangtze River has very high extinction risk within the next 100 years (Huang et al., 2017; Mei et al., 2012).

The estimated porpoise population in the main stem of the Yangtze River was approximately 500 individuals in 2012, representing a decrease of more than 50\% compared to c.1,225 individuals in 2006 (Mei et al., 2014). Given this precipitous decline in the main river, the two adjoining lakes currently preserve more than half of the total wild porpoise population, with approximately 450 porpoises in Poyang Lake and 90 porpoises in Dongting Lake; these two habitats have therefore become critically important sites for Yangtze finless porpoise conservation (Mei et al., 2014; Zhao, Wang, Turvey, Taylor, \& Akamatsu, 2013; Zhao et al., 2008). However, although the two lakes are less industrialized and sustain relatively abundant fishery resources compared to the Yangtze mainstem, local survival of porpoises in both lakes is threatened by heavy water traffic, high intensity of fishing activities, and uncontrolled sand dredging and illegal fishing (Wang, 2009; Wang et al., 2000). 
With the aim of protecting fish resources and reducing by-catch risk to porpoises, local fishery authorities have carried out fishery management actions including implementation of a three-month fishing ban in the two lakes, and enforcement of illegal fishing legislation with regular patrols (Mei et al., 2014). These management measures were expected to benefit porpoises; however, unusual porpoise deaths have been reported frequently from both lakes in recent years under that management (Ding Wang, unpublished data). In particular, a cause of death could be determined for 29 out of 60 dead porpoises collected from 2008 to 2013 from Poyang Lake; of these animals, $11(37.9 \%)$ were directly killed by illegal fishing (one by rolling hooks, three by set nets and seven by electro-fishing gears.), and only one was killed by propeller strike. In Dongting Lake, a cause of death could be determined for seven out of 22 dead porpoises collected from 2008 to 2012, among which four were killed by illegal fishing (two by electro-fishing, one by rolling hooks and one by set nets) and three were killed by propeller strikes. Although relatively few data are available on comparative threats to Yangtze finless porpoises, illegal fishing may therefore be a significant cause of accidental porpoise deaths in the two lakes (Turvey et al., 2013; Zhang, Xian, Wang, \& Wang, 2013). Such high collateral damage on porpoises due to illegal fishing suggests that fishery management efforts have been insufficient to regulate fishing activities, and that improvements in management are therefore urgently needed to prevent further losses of these two important porpoise populations.

Although most environmental laws have seemingly good intentions, not all outcomes have been beneficial. Unintended consequences easily arise from even the most wellintentioned policies (St John, Edwards-Jones, \& Jones, 2010). The unexpected management outcomes are most likely the result of the uncertainty of human behavior (Robbins, McSweeney, Waite, \& Rice, 2006). Although much research on fisher 
behavior was carried out, there remains a lack of focus on the critical role human behavior plays in fisheries management thus contributing to implementation uncertainty (Fulton, Smith, Smith, \& van Putten, 2011). Perverse outcomes have been observed in fisheries managements. Fishing seasons are a commonly used management tool, and reducing the length of the season is often used attempt to control effort. However, reducing season length does not usually reduce effort as much as anticipated, with effort becoming more temporally concentrated as fishers strive to maintain catch levels (Chen, Li, \& Wang, 2012). At the extreme, this leads to situations such as the Bristol Bay red king crab fishery, which in 1996 lasted only four days and still exceeded its preseason guideline harvest level by $65 \%$ (Briand, Heckelei, Matulich, \& Mittelhammer, 2004). To address and reduce the implementation uncertainty that often results, managers will need to incorporate information about resource user behavior beyond the mainly economic objectives that have been included to date (Fulton et al., 2011).

Improved knowledge about fishing activities and the pattern and prevalence of illegal gear use in Poyang Lake and Dongting Lake can help to identify weaknesses in current management, and provide guidance for more effective management plans in the future. One widely-used approach to collect such information is through social surveys among local communities (Turvey, Barrett, Hao, et al., 2010; Turvey, Barrett, Hart, et al., 2010). Although informants may not provide reliable responses when questioned about sensitive subjects such as illegal fishing, this issue can be reduced by careful survey design (Nuno \& St. John, 2015). In this study, we conducted an interview survey among local fishers around Poyang Lake and Dongting Lake. We investigated local fishing activities and their potential changes under different fishery management strategies, with the aim of (1) exploring the impacts of local fisheries on 
the Yangtze finless porpoise, and (2) identifying the potential causes of management failure and suggesting more effective management approaches for fisheries and porpoise conservation.

\section{Materials and methods}

\subsection{Interview survey}

We conducted an interview survey around Poyang Lake from 12 - 17 August 2011, and around Dongting Lake from 21 - 26 August 2012; both interview periods avoided the March - June fishing ban period. Interviews were conducted around Poyang Lake in 10 counties and one municipality (Duchang, Gongqingcheng, Jinxian, Hukou, Nanchang, Poyang, Xingzi, Xinjian, Yongxiu and Yugan counties and Jiujiang municipality), and around Dongting Lake in three counties and one municipality (Miluo, Xiangyin and Yueyang counties and Yueyang municipality). These survey areas together cover the main historical range of the Yangtze finless porpoise in these two lakes (Dong et al., 2014; Zhang et al., 2015) (Fig. 1).

We adopted similar interview techniques and methods to those used by Turvey et al. (Turvey, Barrett, Hao, et al., 2010; Turvey, Risley, Barrett, Hao, \& Wang, 2012; Turvey et al., 2013). We selected informants from fishing communities based on their local knowledge and expertise on local fishing activities, with the assistance of local fisheries officials. We only interviewed one individual from each family to ensure independence of interview data, since family members might share their experiences and knowledge of fishing. Interviews were conducted on a one-to-one basis in an informal and relaxed setting, and followed a structured Chinese-language questionnaire with well-defined questions in a set sequence that took approximately 
20 - 30 minutes to complete. All interviewers were well-trained and possessed good communication skills and interviewing techniques, and conducted interviews with full respect to local customs and culture and minimal disruption to informants' business.

As part of a wider series of interview questions (Table S1), we asked informants about their age and education level, their perceptions on changes of local fish resources and fishing activities, their working hours (including how many hours per day they spent fishing, and whether they fish during nighttime), and their fishing gear use (including what gears they had used in the past, and what gears they and other fishers had used during the previous three years). In particular, we asked whether they had seen other fishers using set nets, seine nets and electro-fishing, three illegal fishing methods that are commonly used in Poyang and Dongting Lakes, during the previous three years. We also asked informants about what sort of compensation they would prefer if their fishing region was protected as a nature reserve.

\subsection{Data analysis}

We summarized basic information for each lake on ages and education levels of fishers, reported usage of illegal gears, and compensation preferences. We analyzed survey data using chi-squared tests and post hoc tests in R 3.1.5 (R Development Core Team, 2008) to explore the potential influence of 1) age on nighttime fishing activities, 2) education level on the use of illegal gears, and 3) age on compensation preferences.

\subsection{Data availability}

The data that support the findings of this study are available from the corresponding author upon request. 


\section{Results}

\subsection{Age structure and education level of informants}

In total, we interviewed 313 informants around Poyang Lake, and 313 around Dongting Lake. Not all informants answered all questions in the questionnaire. All informants were male, whom were the main representative of the fishermen's families, and the age structure of informants from the two regions was similar, with informants from Poyang Lake ranging in age from $22-80$ (mean $=49.3$ years, $\mathrm{SD}=10.8 ; \mathrm{Fig}$ 2a) and informants from Dongting Lake ranging in age from $17-77$ (mean $=47.9$ years, $\mathrm{SD}=10.3$; Fig 2b).

Informants had a generally low education level in both regions: $45 \%$ of all informants in Poyang Lake $(n=311)$ and $35.4 \%$ in Dongting Lake $(n=313)$ did not complete elementary education, while $30.5 \%$ in Poyang Lake and $27.5 \%$ in Dongting Lake had only completed elementary education. Only approximately one-third of informants from both regions (30.5\% in Poyang Lake, 37.1\% in Dongting Lake) had completed secondary or higher education. There is a significant age-related difference in education levels in both regions (Poyang: $\chi^{2}(6, \mathrm{~N}=311)=24.74, \mathrm{p}<0.001$; Dongting: $\left.\chi^{2}(6, N=313)=24.23, p<0.001\right)$, with elder informants less likely to have completed elementary or higher education: $64.6 \%$ of informants in Poyang Lake and $59.5 \%$ in Donting Lake had not completed elementary education in the oldest age group (60 years or older), whereas only $22.4 \%$ of informants in Poyang Lake and 19.6\% in Dongting Lake had not completed elementary education in the youngest age group (30 years and below).

\subsection{Changes of fish catch and number of fishing vessels}

When asked about their perceptions of fish catch changes, $92.8 \%$ of all informants (n 
$=308)$ in Poyang Lake and $77.3 \%$ of all informants $(n=313)$ in Dongting Lake considered that their current fish catch was less than that in the past. When asked about their perceptions of changes in the number of vessels, nearly half of all informants in Poyang Lake $(46.3 \%, \mathrm{n}=305)$ and more than half of all informants in Dongting Lake $(63.3 \%, \mathrm{n}=311)$ considered that vessel numbers had remained constant or increased over time.

\subsection{Illegal fishing gear usage}

Levels of reported usage of legal and illegal fishing gears in Poyang and Dongting Lakes are given in Figure S1 (full results of fishing gear using status, $n=298$ in Poyang region, $\mathrm{n}=306$ in Dongting region). In both regions, the proportion of informants who reported that they had used a specific type of illegal gear in the past was more than twice the proportion of informants who reported that they still used it, except for set nets in Poyang Lake $(22.8 \%$ in the past against $17.1 \%$ at the time of interviews; Fig. 3a) and trawl nets in Dongting Lake (12.4\% in the past against $7.5 \%$ at the time of interviews; Fig. 3b). The proportion of informants who reported that specific illegal gears were used by other fishers during the previous three years was similar to the proportion of informants who reported that they themselves still used each gear. According to informants who reported that they currently used illegal gears, set nets and rolling hooks were the most widely used illegal gears in both regions (both used by $17.1 \%$ of informants in Poyang Lake, and by $21.6 \%$ and $16.7 \%$ of informants respectively in Dongting Lake; Fig. 3), while other illegal gears were reportedly used by only $1-7 \%$ of informants for both regions.

A higher proportion of informants reported that they had seen other fishers using illegal gears when questioned in a specific manner (i.e., when asked whether they had 
ever seen other fishers using set nets, seine nets or electro-fishing gear in the previous three years) compared to when questioned in a more general way (i.e., when asked to nominate gears recently used by other fishers). For instance, when informants from Poyang Lake were asked to identify illegal gears used by other fishers in the previous three years, only $4.0 \%$ of all informants $(n=298)$ identified electro-fishing gear, but when questioned in a more specific manner about whether they had seen other fishers using electro-fishing gear in the previous three years, $20.8 \%$ reported that they had (Fig. 3a).

We aggregated the proportion of informants who reported the use of at least one illegal gear when asked about "past use", "current use", "currently used by other fishers", and/or "seen other fishers using illegal gears" respectively for both lakes. In total, $37.6 \%$ of all informants in Poyang Lake (Fig. 4a) and $46.1 \%$ of all informants in Dongting Lake (Fig. 4b) reported that themselves had used illegal gears during the previous three years.

\subsection{Timing of fishing activities}

In total, $225(86.7 \%)$ informants in Poyang Lake $(n=294)$ and $201(66.8 \%)$ informants in Dongting Lake $(\mathrm{n}=301)$ reported that their fishing activities were partially or totally conducted during nighttime (the period from $6 \mathrm{pm}$ to $6 \mathrm{am}$ ). The percentage of informants that conducted fishing at night did not differ by age (Poyang Lake: $\chi^{2}(3, \mathrm{~N}=294)=2.09, \mathrm{p}=0.55$; Dongting Lake: $\chi^{2}(3, \mathrm{~N}=301)=0.95, \mathrm{p}=$ $0.81)$.

\subsection{Preferred compensation}

Informants' compensation preferences were similar in both regions. Monetary 
compensation was the most popular choice, with approximately $60 \%$ of all informants $(n=311)$ in Poyang Lake and 69\% of all informants $(n=301)$ in Dongting Lake selecting this choice (Fig. 5). Compensation with aquaculture areas was the second most popular choice, and more than $30 \%$ of all informants preferred this form of compensation for each region. Only about $7 \%$ of informants from both regions preferred compensation with arable land. A further 5.5\% of informants from Poyang Lake and $10.6 \%$ of informants from Dongting Lake indicated other forms of preferred compensation, including being offered new jobs, or continuing to make a living by fishing. Informants' choices of compensation approach did not differ by age (Poyang Lake: $\chi^{2}(9, \mathrm{~N}=311)=3.90, \mathrm{p}=0.92$; Dongting Lake: $\chi^{2}(9, \mathrm{~N}=301)=6.23, \mathrm{p}=$ $0.72)$.

\section{Discussion}

Enforcement actions, such as patrols against illegal fishing in Poyang and Dongting Lakes, represent a direct and widely-used approach to address problems of illegal natural resource exploitation. However, enforcement actions constitute a negative behavioral incentive, and their effectiveness in detecting illegal activities may be reduced if conflicting financial incentives motivate such activities to be carried out more secretively to avoid punishment (Arias, 2015; Stern, 2008). Based on the data collected in this study, here we present six scenarios of potential consequences that could result from increased patrolling in Poyang and Dongting Lakes, and we examine the likelihood of each scenario based on our survey results to identify possible weaknesses of the conservation management (Table 1).

If there are no enforcement actions (patrols) in Poyang or Dongting Lakes, fishers can operate freely at any time of day or night. We assume that they may be inclined to 
practice daytime fishing, since the use of some illegal fishing gears (e.g. electrofishing equipment) can be hazardous and requires cooperative behaviour and potential improved visibility. However, when patrols are in place, illegal fishing is likely to be reduced or completely removed during the daytime. For each of these two behavioural responses (reduced and removed), we also consider the further three associated scenarios: no illegal fishing at night, unchanged illegal fishing intensity at night compared to a scenario with no patrols, and intensified illegal fishing at night (Table $1)$.

The first scenario (Sc1, Table 1) represents a situation where patrolling is completely effective, and that has completely eliminated illegal fishing activities during both day and night. This scenario is considered highly unlikely, since our survey data show that fishers report using illegal gears widely in both lakes. Furthermore, the levels of illegal gear usage that were reported directly in our study are likely to represent substantial underestimates of true levels of illegal fishing, as our data also show a significant difference between answers to different types of questions about illegal gear use observed among other fishers, depending on whether the question was posed in general terms or referred to the informant's observations of specific illegal gear types. We therefore consider that actual use of illegal gears is likely to be much higher than the reported $37.6 \%$ of informants in Poyang Lake and $46.1 \%$ in Dongting Lake. As there are 18,000 registered fishing families in Poyang Lake and 5,554 in Dongting Lake, there could therefore be thousands of boats still conducting illegal fishing across the study regions.

The second scenario (Sc2) represents a situation where patrolling has been effective in removing illegal fishing during daytime, but the intensity of illegal fishing during 
nighttime has not changed compared to the period before patrols began. Based on our data on informant perceptions of changes to fish catches and vessel numbers, we consider that this scenario is also unlikely to be correct. Fishers in this study considered that fishery resources have declined in both lakes, which is consistent with independent fisheries survey data (Huang, Wu, \& Li, 2013; Ru \& Liu, 2013), and most informants also considered that numbers of fishing vessels in both regions had not decreased. Therefore, whereas fish resources have declined, the number of local fishers does not appear to have declined. In this case, even if fishers maintain an unchanged level of nighttime illegal fishing, the total fish catch per vessel will be less than the original level before patrols started, given the complete removal of daytime illegal fishing. Such a decrease in overall fish catch will inevitably affect financial profits and local fishing community livelihoods (Fulton et al., 2011), and so this situation is unlikely to persist long-term.

In the third scenario (Sc3), patrolling is considered to lead to effective removal of illegal fishing during daytime, but intensified illegal fishing effort during nighttime (compensatory fishing). We consider this scenario to be a more likely consequence of patrolling than $\mathrm{Sc} 1-\mathrm{Sc} 2$. In common with $\mathrm{Sc} 2$, fish resources have declined but vessel numbers indicate that local communities that make a living from fishing have not declined, and so local fishers whom don't have the skillset to switch livelihoods because of limited education, have to increase the intensity of illegal fishing during nighttime to maintain their livelihoods as well as avoiding patrols and escaping punishment. Indeed, our data on informants' fishing times suggests that most fishers in the two lakes conduct nighttime fishing, which is related to the long tradition of "night fishing, morning selling" held by local fishing communities and associated with proficient night-fishing skills passed down between generations. 
The final three scenarios all consider that illegal fishing during daytime has been reduced but not completely eliminated by patrolling, with three possible fishing behaviors during nighttime: 1) no illegal fishing at night (Sc4), unchanged illegal fishing intensity at night compared to before patrolling started (Sc5), and intensified illegal fishing at night (Sc6). We consider that the respective likelihoods of Sc4 Sc6 are comparable to the respective likelihoods of Sc1 - Sc3, with Sc4 very unlikely, Sc5 relatively unlikely, and Sc6 the most likely. As we consider that illegal fishing activities can be effectively reduced when patrolling is present, limited ongoing illegal fishing activities in Sc4 - Sc6 would not be expected to lead to a substantial increase in daytime fish catch, suggesting that such limited daytime illegal fishing may not affect fishing activities during night-time.

We suggest that the most likely scenarios for explaining illegal fishing behaviour in Poyang and Dongting Lakes are that, when enhanced patrolling is in place, fishers might be expected to reduce or cease illegal fishing activities during daytime, and conversely to increase illegal fishing activities during nighttime when there are no patrols (Sc3 and Sc6). These scenarios may have implications for the survival of Yangtze finless porpoise populations in the two lakes. Even if fishers generally do not intend to catch or harm porpoises on purpose (Turvey et al. 2013), unintentional injuries to porpoises may cause by the animals get entangled or interact with gear underwater. Yangtze finless porpoises have been shown to be primarily nocturnal and crepuscular feeders, and more active during the night and dawn (Akamatsu, Wang, Wang, Li, \& Dong, 2010; Kimura et al., 2013; Wang, Akamatsu, Wang, \& Wang, 2014). The potential temporal overlap between porpoise foraging time and illegal fishing time may therefore lead to a higher risk of collateral damage on porpoises (Jefferson \& Curry, 1994). 
The scenarios based on results from our field study reveal that some conservation management practices, in this case daytime patrols in Poyang and Dongting Lakes, can be ineffective and may even have unforeseen negative conservation consequences, when they are developed without thorough consideration of the behaviours of both threatened species and local resource users who can adapt their activities in response to new policies (Briand et al., 2004).

Given the ineffectiveness of the daytime patrols, seeking alternative management strategies to remove illegal fishing is strongly recommended. However, to our knowledge, the overall management strategy in Poyang Lake remains unchanged, which still focuses on strengthening the daytime patrols; therefore, the problem of intense nighttime illgal fishing remains unsolved. In contrast, Dongting Lake has seen a sharply decrease of illegal fishing activities by introducing additional nighttime patrols. With manpower and material assistance from two local non-government ognizations (both established after 2012), the local fishery authority of Dongting Lake has been able to extend their patrol time to prevent nighttime illegal fishing. The extended patrol strategy, together with other environmental management actions such as better management of sand mining and habitat restoration etc. , are presumably the primary reason that lead to an increase of the Yangtze finless porporse population in Dongting Lake (2017 IWC report, page 69). In spite of the effectiveness, we discourage using nighttime patrol as a long-term management approach since it is a highly hazardous approach to both patrol personnels and fishers due to poor lighting conditions and complicated ship traffics. Furthermore, although these strengthened enforcement actions, or other proposed monitoring approaches (e.g. deploying GPS devices on registered boats) may lead to greater success, they cannot fundamentally reconcile the long-standing conflicts between conservation and the fishermen's 
livelihood. Policy-making on conservation and natural resource management also requires a comprehensive consideration of community interest and human well-being for long-term success and sustainability.

In this system, securing fishers' livelihoods may provide an alternative, practical and fundamental solution to illegal fishing. Our survey showed the fishing communities in both Poyang and Dongting Lakes represent ageing populations with relatively low education levels. Several respondents in our sample who were considerably older than sixty reported that they still had to make a living by fishing, because they lacked any other livelihood guarantees. With large fisher populations and declining fish resources, the existing fishing industry in both lakes is unlikely to be sustainable. We therefore recommend a complete fishing ban in both lakes, to be associated with a thorough retraining and alternative livelihood scheme and compensation policy for the region's existing fishing communities. For example, younger fishers could be provided with vocational skills training to adapt themselves to new jobs, and older fishers could be vouchsafed retirement with basic standards of livelihood guarantee. Our data show that monetary compensation and non-monetary compensation with aquaculture areas are the two most popular choices among the region's fishers. Further understanding of the various needs of fishing communities around Poyang and Dongting Lakes will be required, to help inform more specific, nuanced and effective decisions and management practices for achieving the ultimate conservation goals of protecting fish resources and the Critically Endangered Yangtze finless porpoise. 


\section{Acknowledgements}

This work was supported by grants from the National Natural Science Foundation of China (Nos. 31430080, 31500456), the National Key Programme of Research and Development, Ministry of Science and Technology (2016YFC0503200), and Ocean Park Conservation Foundation, Hong Kong (No. MM10_1112, MM13_1213, MM03_1516). We sincerely thank Dr. Randall Reeves for his constructed suggestions on this article. We also sincerely thank Zhengyi Qian, Yongtao Li, Xiaoling Wan and Shiyong Wang for participating in our interview survey. All authors declare that they have no conflict of interest. 


\section{Reference}

Akamatsu, T., Wang, D., Wang, K., Li, S., \& Dong, S. (2010). Scanning sonar of rolling porpoises during prey capture dives. Journa of Experimental Biology, 213, 146152.

Arias, A. (2015). Understanding and managing compliance in the nature conservation context. Journal of Environmental Management, 153, 134-143.

Briand, G., Heckelei, T., Matulich, S. C., \& Mittelhammer, R. C. (2004). Managing fishing power: the case of Alaska red king crab (Paralithodes camtschaticus). Canadian journal of fisheries and aquatic sciences, 61, 43-53.

Chen, D., Li, S., \& Wang, K. (2012). Enhancement and conservation of inland fisheries resources in China. Environmental Biology of Fishes, 93, 531-545.

Dong, L., Wang, D., Wang, K., Mei, Z., Wang, S., Akamatsu, T., \& Kimura, S. (2014). Yangtze finless porpoises along the main channel of Poyang Lake, China: Implications for conservation. Marine Mammal Science, 31, 612-628.

Fulton, E. A., Smith, A. D. M., Smith, D. C., \& van Putten, I. E. (2011). Human behaviour: the key source of uncertainty in fisheries management. Fish and Fisheries, 12, 2-17.

Gao, A., \& Zhou, K. (1995). Geographical variation of external measurements and three subspecies of Neophocaena phocaenoides in Chinese waters. Acta Theriologica Sinica, 15, 81-92.

Huang, L. L., Wu, Z. Q., \& Li, J. H. (2013). Fish fauna, biogeography and conservation of freshwater fish in Poyang Lake Basin, China. Environmental Biology of Fishes, 96, 1229-1243.

Huang, S.-L., Mei, Z., Hao, Y., Zheng, J., Wang, K., \& Wang, D. (2017). Saving the Yangtze finless porpoise: Time is rapidly running out. Biological Conservation, 
$210,40-46$.

Jefferson, T. A., \& Curry, B. E. (1994). A global review of porpoise (Cetacea Phocoenidae) mortality in gillnets. Biological Conservation, 67, 167-183.

Jefferson, T. A., \& Wang, J. Y. (2011). Revision of the taxonomy of finless porpoises (genus Neophocaena): the existence of two species. Journal of Marine Animals and Their Ecology, 4, 3-16.

Kimura, S., Akamatsu, T., Wang, D., Li, S., Wang, K., \& Yoda, K. (2013). Variation in the production rate of biosonar signals in freshwater porpoises. The Journal of the Acoustical Society of America, 133, 3128-3134.

Mei, Z., Huang, S. L., Hao, Y., Turvey, S. T., Gong, W., \& Wang, D. (2012). Accelerating population decline of Yangtze finless porpoise (Neophocaena asiaeorientalis asiaeorientalis). Biological Conservation, 153, 192-200.

Mei, Z., Zhang, X., Huang, S.-L., Zhao, X., Hao, Y., Zhang, L., . . Wang, D. (2014). The Yangtze finless porpoise: On an accelerating path to extinction? Biological Conservation, 172, 117-123.

Nuno, A., \& St. John, F. A. V. (2015). How to ask sensitive questions in conservation: A review of specialized questioning techniques. Biological Conservation, 189, $5-15$.

Robbins, P., McSweeney, K., Waite, T., \& Rice, J. (2006). Even Conservation Rules Are Made to Be Broken: Implications for Biodiversity. Environmental Management, 37, 162-169.

Ru, H. J., \& Liu, X. Q. (2013). River-lake migration of fishes in Dongting Lake area of the Yangtze floodplain. Journal of Applied Ichthyology, 29, 594-601.

St John, F. A. V., Edwards-Jones, G., \& Jones, J. P. G. (2010). Conservation and human behaviour: lessons from social psychology. Wildlife Research, 37, 658-667. 
Stern, M. J. (2008). Coercion, voluntary compliance and protest: the role of trust and legitimacy in combating local opposition to protected areas. Environmental conservation, 35, 200-210.

Turvey, S., Barrett, L., Hao, Y., Zhang, L., Zhang, X., Wang, X., . . Wang, D. (2010). Rapidly shifting baselines in Yangtze fishing communities and local memory of extinct species. Conserv Biol, 24, 778-787.

Turvey, S. T., Barrett, L. A., Hart, T., Collen, B., Hao, Y., Zhang, L., . . Zhou, K. (2010). Spatial and temporal extinction dynamics in a freshwater cetacean. Proceedings of the Royal Society B: Biological Sciences, 277, 3139-3147.

Turvey, S. T., Pitman, R. L., Taylor, B. L., Barlow, J., Akamatsu, T., Barrett, L. A., . . . Wang, D. (2007). First human-caused extinction of a cetacean species? Biology Letters, 3, 537-540.

Turvey, S. T., Risley, C. L., Barrett, L. A., Hao, Y., \& Wang, D. (2012). River dolphins can act as population trend indicators in degraded freshwater systems. PLoS One, 7, e37902.

Turvey, S. T., Risley, C. L., Moore, J. E., Barrett, L. A., Yujiang, H., Xiujiang, Z., . . . Ding, W. (2013). Can local ecological knowledge be used to assess status and extinction drivers in a threatened freshwater cetacean? Biological Conservation, $157,352-360$.

Wang, D. (2009). Population status, threats and conservation of the Yangtze finless porpoise. Chinese Science Bulletin, 54, 3473-3484.

Wang, D., Liu, R., Zhang, X., Yang, J., Wei, Z., Zhao, Q., . . Xiaoqiang, W. (2000). Status and conservation of the Yangtze finless porpoise. Biology and conservation of freshwater cetaceans in Asia, 81-85.

Wang, Z., Akamatsu, T., Wang, K., \& Wang, D. (2014). The Diel Rhythms of Biosonar 
Behavior in the Yangtze Finless Porpoise (Neophocaena asiaeorientalis asiaeorientalis) in the Port of the Yangtze River: The Correlation between Prey Availability and Boat Traffic. PLoS One, 9, e97907.

Zhang, X., Xian, Y., Wang, L., \& Wang, D. (2013). Behaviour and habitat selection of yangtze finless porpoises in Dongting Lake, China, and the adjacent waters: impact of human activity. Pakistan Journal of Zooogyl, 45, 635-642.

Zhang, X., Yu, D., Wang, H., Wan, A., Chen, M., Tao, F., \& Song, Z. (2015). Effects of fish community on occurrences of Yangtze finless porpoise in confluence of the Yangtze and Wanhe Rivers. Environmental Science and Pollution Research, 22, 9524-9533.

Zhao, X., Wang, D., Turvey, S., Taylor, B., \& Akamatsu, T. (2013). Distribution patterns of Yangtze finless porpoises in the Yangtze River: implications for reserve management. Animal Conservation, 16, 509-518.

Zhao, X. J., Barlow, J., Taylor, B. L., Pitman, R. L., Wang, K. X., Wei, Z., . . Wang, D. (2008). Abundance and conservation status of the Yangtze finless porpoise in the Yangtze River, China. Biological Conservation, 141, 3006-3018. 
Table 1 Six scenarios $(\mathrm{Sc} 1-6)$ of potential consequences of the enhanced daytime patrolling in Poyang and Dongting Lakes. Sc1 represents the situation that patrolling is completely effective in removing illegal fishing during day and night. Sc2 represents the situation that patrolling is effective in removing illegal fishing during daytime, but the intensity of illegal fishing during nighttime remains unchanged compared to pre-patrol period. Sc3 represents the situation that patrolling is effective to remove illegal fishing during daytime, but intensified illegal fishing occurs during nighttime. Sc4 - 6 assumes illegal fishing during daytime has been reduced but not completely eliminated, with three possible fishing behaviors during nighttime: 1) no illegal fishing (Sc4), unchanged intensity of illegal fishing (Sc5), and intensified illegal fishing (Sc6). Y indicates that this type of fishing method will occur. N indicates that this type of fishing method does not occur.U-L means unlikely, L-L means less likely, and M-L means most likely.

\begin{tabular}{|c|c|c|c|c|c|c|c|c|}
\hline & $\begin{array}{l}\text { Fishing } \\
\text { type }\end{array}$ & $\begin{array}{l}\text { No } \\
\text { patrol }\end{array}$ & $\mathrm{Sc} 1$ & $\mathrm{Sc} 2$ & $\mathrm{Sc} 3$ & Sc4 & Sc5 & Sc6 \\
\hline \multirow{2}{*}{ Daytime } & Legal & $\mathrm{Y}$ & $\mathrm{Y}$ & $\mathrm{Y}$ & $\mathrm{Y}$ & $\mathrm{Y}$ & $\mathrm{Y}$ & $\mathrm{Y}$ \\
\hline & Illegal & $\mathrm{Y}$ & $\mathrm{N}$ & $\mathrm{N}$ & $\mathrm{N}$ & $\mathrm{Y}^{\dagger}$ & $\mathrm{Y}^{\dagger}$ & $\mathrm{Y}^{\dagger}$ \\
\hline \multirow{2}{*}{ Night } & Legal & $\mathrm{Y}$ & $\mathrm{Y}$ & $\mathrm{Y}$ & $\mathrm{Y}$ & $\mathrm{Y}$ & $\mathrm{Y}$ & $\mathrm{Y}$ \\
\hline & Illegal & $\mathrm{Y}$ & $\mathrm{N}$ & $\mathrm{Y}$ & $\mathrm{Y}^{\ddagger}$ & $\mathrm{N}$ & $\mathrm{Y}$ & $\mathrm{Y}^{\ddagger}$ \\
\hline Possibilities & & & U-L & L-L & M-L & U-L & L-L & M-L \\
\hline Threat & & Highest & Low & High & Highest & Low & High & Highest \\
\hline
\end{tabular}




\section{Figure legends}

Fig 1 Interview locations around Poyang and Dongting Lakes.

Fig 2 Age structure of informants and number of informants with different education levels within each age group for (a) Poyang Lake and (b) Dongting Lake.

Fig 3 Proportion of informants who identified specific gears that they used in the past, that they have used during the previous three years, that other fishers have used during the previous three years, and that they have seen other fishers using, for (a) Poyang Lake and (b) Dongting Lake.

Fig 4 Proportion of informants who identified any of three named illegal gears (set nets, seine nets, electro-fishing gear) that they used in the past, that they have used during the previous three years, that other fishers have used during the previous three years, and that they have seen other fishers using, for Poyang Lake and Dongting Lake.

Fig 5 Proportion of informants who preferred compensation with arable lands, with aquaculture areas, with money, or with other preferred compensations, for Poyang Lake and Dongting Lake. 